\title{
Colon perforation due to cytomegalovirus infection in a patient with idiopathic hypereosinophilic syndrome: a case report
}

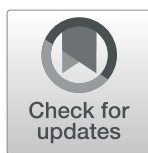

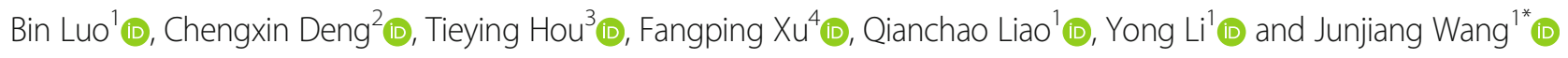

\begin{abstract}
Background: Hypereosinophilic syndrome (HES) is a very rare disease and usually treated with corticosteroids. Gastrointestinal (Gl) cytomegalovirus (CMV) infection is also rare but frequent in patients with immunocompromised status. These two related diseases present with similar manifestations, and may result in a life-threatening complication: perforation. However, the treatment strategies differ greatly. Here, we report a case of colon perforation due to cytomegalovirus infection in a patient with idiopathic HES.

Case presentation: A 41-year-old man with a history of HES was transferred to our hospital due to an acute onset of abdominal pain. During the treatment course of HES, this patient received CMV-DNA test with a result of $<2000$ copies/ml. Computed tomography (CT) suggested colon perforation. An emergency surgery was performed immediately. Pathological diagnosis revealed CMV infection and infiltration of eosinophils. This patient received both anti-CMV therapy and immunosuppression therapy. Subsequently, the patient recovered and was discharged 25 days after the operation.
\end{abstract}

Conclusion: During the course of HES treatment, CMV infection should be reconsidered if digestive symptoms relapse.

Keywords: Colon perforation, Cytomegalovirus infection, Idiopathic hypereosinophilic syndrome, Immunosuppression therapy, Case report

\section{Background}

Hypereosinophilia (HE) is defined as an absolute count of peripheral blood eosinophils greater than $1500 / \mathrm{mm}^{3}$, and it may be associated with tissue injury [1]. Hypereosinophilic syndrome (HES) is a very rare disease with a reported age-adjusted incidence rate of 0.036 per 100 , 000 [2]. The first-line treatment for HES is steroids. Cytomegalovirus (CMV) is a double-stranded DNA virus in the herpesvirus family $[3,4]$. The CMV infection rate in the general population varies from 40 to $100 \%$ [5-7]. However, initial infection of CMV is frequently

\footnotetext{
* Correspondence: sywangjunjiang@scut.edu.cn

'Department of General Surgery, Guangdong Provincial People's Hospital, Guangdong Academy of Medical Sciences, Guangzhou 510080, China

Full list of author information is available at the end of the article
}

asymptomatic, and it may become latent for life in immunocompetent hosts. Symptomatic gastrointestinal cytomegalovirus (GI-CMV) infection is rare, but common among patients in immunocompromised status [8]. These two related diseases can present with similar symptoms of abdominal pain, diarrhea, and GI bleeding. However, the treatment strategy for these two diseases differs greatly. Incorrect medications may result in lifethreatening complications. Here, we report a case of colon perforation due to CMV infection in a patient with HES.

\section{Case presentation}

The patient was a 41-year-old Asian man, who suffered from diarrhea and skin itch 4 years ago and was 


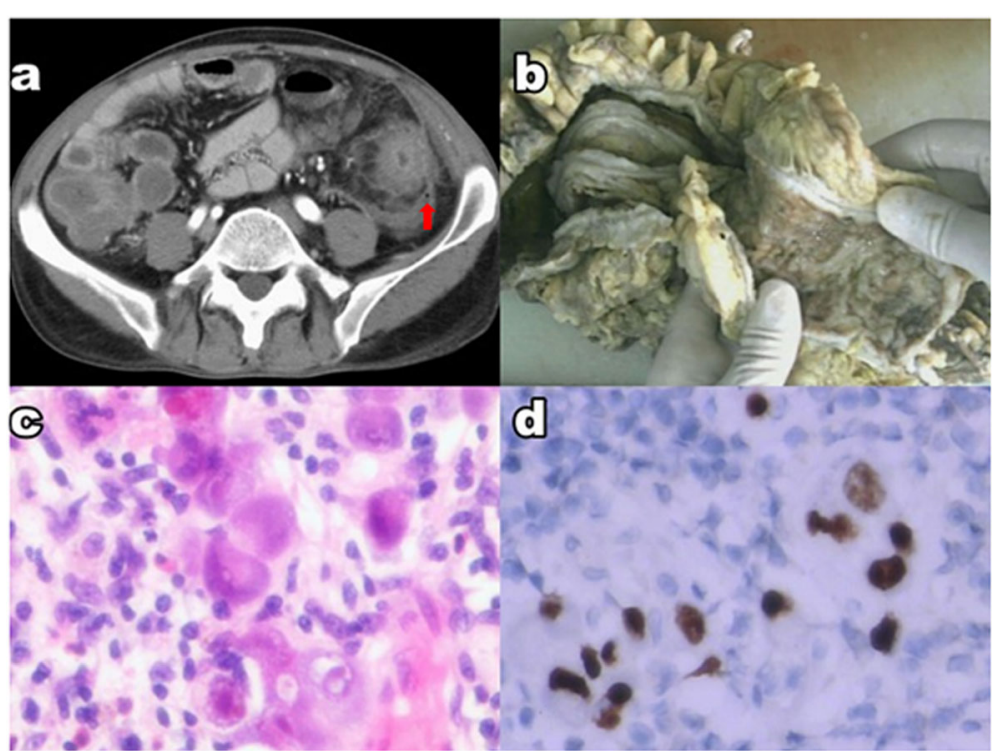

Fig. 1 a Swollen descending colon wall and free air (red arrow). b Swollen bowel wall, deep ulcer and mucosal erosion on specimen. c Massive virus inclusion body. $\mathbf{d}$ Immunohistochemical staining confirmed the infection of CMV

diagnosed with HES. He received pharmacotherapy of methylprednisolone. The initial dosage was $40 \mathrm{mg}$ per day and was gradually reduced to $28 \mathrm{mg}$ per day. During the course of immunosuppression therapy, the patient received CMV-DNA test with a result of $<2000$ copies/ $\mathrm{ml}$. This patient was transferred to our hospital due to an acute onset of abdominal pain for $3 \mathrm{~h}$. He denied a history of parasite infection. Stool-rt was performed and ova weren't found. There was no history of drug or food allergies or any other significant medical history. The physical examination found skin rashes over the entire body and typical signs of peritonitis. Laboratory examinations showed increased CRP levels of $102 \mathrm{mg} / \mathrm{L}$. The complete blood cell count revealed a white blood cell count of $27.93 \% 10^{9} / \mathrm{L}$ with a differential of $60.0 \%$ eosinophils. The total level of IgE was greater than $2000 \mathrm{IU} / \mathrm{ml}$. Abdominal contrast enhanced CT revealed that the descending colon wall was swollen and free air existed (Fig. 1a). The patient underwent an emergency operation of left hemicolectomy immediately. Swollen bowel wall, multiple deep ulcers and mucosal erosions were found in specimens (Fig. 1b). Pathological diagnosis revealed massive virus inclusion bodies (Fig. 1c) and infiltration of eosinophils, but without any evidence of thrombus, vasculitis or occlusion. Immunohistochemical staining confirmed CMV infection (Fig. 1d). CMV-DNA test was performed again postoperatively and the copy number of CMV in blood was $8.02 * 10^{4} / \mathrm{ml}$. The patient received Ganciclovir ( $5 \mathrm{mg} / \mathrm{kg}$, twice daily for 21 days) therapy, and dexamethasone (5 $\mathrm{mg}$ per day) was also taken to control the symptoms of HES. Finally, the patient was discharged from our hospital 25 days after the operation.
The CMV-PCR test results were lower than 2000 copies per milliliter, and the percentage of eosinophils decreased to the normal range.

\section{Discussions and conclusions}

To make a diagnosis of HES, the absolute count of eosinophils $>1500 / \mathrm{mm}^{3}$ must persist longer than 6 months, tissue damage must be present, and other diseases must be excluded $[1,9]$ (Table 1). Theoretically, all organs are susceptible to the infiltration of sustained eosinophilia. Dermatologic involvement is the most common (69\%), followed by pulmonary (44\%) and gastrointestinal (38\%) involvement [10]. In our case, multiple organs were infiltrated by eosinophils, including the stomach, colon, tonsil, cervical lymph nodes and perididymis (Fig. 2).

Table 1 Diagnosis of idiopathic hypereosinophilic syndrome (HES)

Exclusion of the following diseases

1. Reactive eosinophilia

2. Lymphocyte-variant hypereosinophilia (cytokine-producing, immunophenotypically-aberrant T-cell population)

3. Chronic eosinophilic leukemia, NOS

4. WHO-defined myeloid malignancies associated eosinophilia (e.g. MDS, MPNs, MDS/MPNs, or AML)

5. Eosinophilia-associated MPNs or AML/ALL with rearrangements of PDGFRA, PDGFRB, or FGR1.

Abbreviations: NOS not other specified, MDS myelodysplastic syndrome, MPNs myeloproliferative neoplasms, $A M L$ acute myeloid leukemia, $A L L$ acute lymphoblastic leukemia, PDGFRA platelet-derived growth factor receptor alpha, PDGFRB platelet-derived growth factor receptor beta, FGR1 fibroblast growth factor receptor 1 


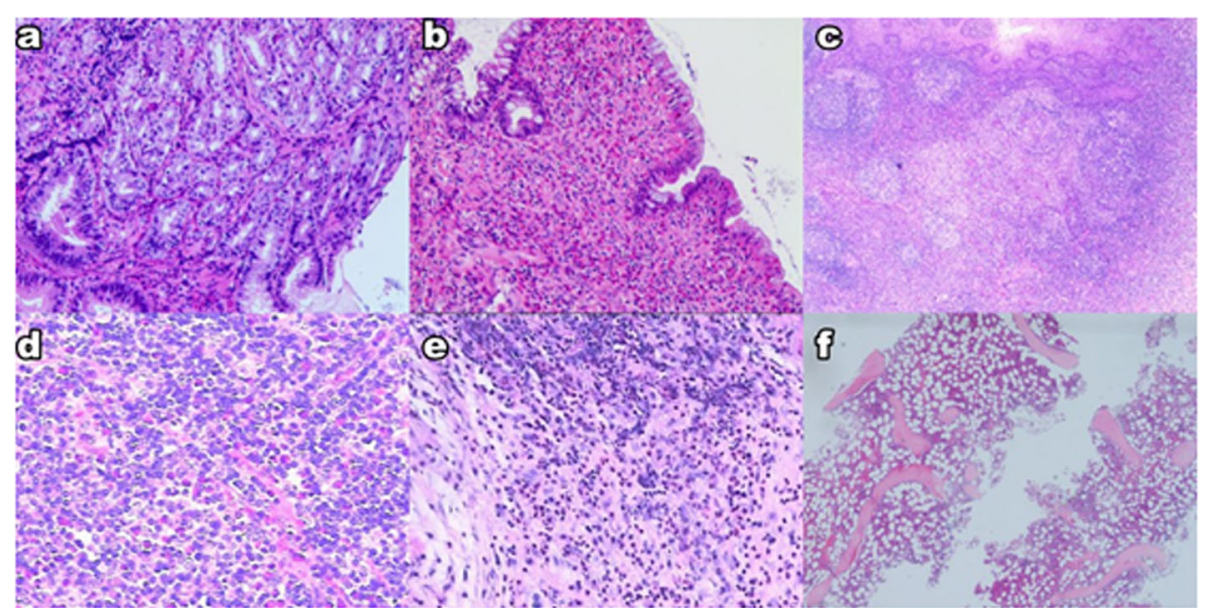

Fig. 2 Massive eosinophil infiltration into multiple organs. a Stomach. b Colon. c Tonsil. d Cervical lymph node. e Periorchium. f Bone marrow

The essential goal of the therapy is to alleviate eosinophil-mediated organ damage. Corticosteroids are the first-line therapy for patients with symptoms and organ involvement. Hydroxyurea and interferon-alpha have demonstrated efficacy as initial treatment and steroid-refractory cases [1]. Long-term corticosteroid treatment may suppress patients' immune systems, making them susceptible to microorganisms.

Latent CMV infection may become active in the presence of acute stressful conditions or in the case of severe or prolonged immunosuppression, for example, HIVpositive patients and transplant recipients. The GI tract is the most frequent site infected by CMV $[11,12]$. It is characteristic to find multiple ulcers during endoscopy in GI-CMV which can result in gastrointestinal perforation, which is life-threatening once it occurs.

HES, the utilization of corticosteroids and GI-CMV infection can damage the gastrointestinal mucosa and cause perforation. Two cases of digestive tract perforation associated with hypereosinophilic syndrome (HES) have been reported. And digestive tract perforation was attributed to acute thrombosis $[13,14]$. In this case, because pathological examination revealed a massive CMV inclusion body and a few infiltration of eosinophils, but without any evidence of thrombus, vasculitis or occlusion, we concluded that acute colon perforation resulted from cytomegalovirus infection after immunosuppression therapy.

Abdominal pain, diarrhea and GI bleeding are the manifestations of both HES and CMV infection, but the treatment strategies for these two diseases differ greatly from each other. In this case, when the symptoms of abdominal pain, diarrhea and GI bleeding relapsed, the dosage of corticosteroids was increased. However, these symptoms were actually caused by CMV infection. Incorrect immunosuppression therapy will exacerbate the infection of $\mathrm{CMV}$, and lead to colon perforation.
The 'gold standard' assay for CMV is the CMVantigenemia (AG) test with a reported sensitivity and specificity of 70-90\% [15]. Because the levels of CMVAG are proportional to disease severity and treatment response, the CMV-AG test can be utilized as an indicator for monitoring active CMV infection and guiding treatment [16]. CMV-PCR is a new method to detect active CMV infection which has comparable sensitivity and specificity $[17,18]$. In this case, the onset of abdominal pain, diarrhea during immunosuppression therapy may suggest that latent CMV infection became active. However, the optimal treatment time was missed. Hence, if digestive symptoms relapse during the course of HES treatment, CMV infection should be reconsidered even though the latest result of CMV-DNA test was negative.

\section{Abbreviations \\ HES: Hypereosinophilic syndrome; Gl: Gastrointestinal; CMV: Cytomegalovirus; CT: Computed tomography; AG: Antigenemia; CRP: C-reaction protein; PDGF RA: Platelet-derived growth factor receptor alpha; PDGFRB: Platelet-derived growth factor receptor beta; FGR1: Fibroblast growth factor receptor 1}

\section{Acknowledgements}

We acknowledged Miss Zhan for contribution to figure editing.

\section{Authors' contributions}

$\mathrm{BL}, \mathrm{QCL}, \mathrm{YL}$ and JJW performed the surgery. BL reviewed the literature and contributed to the manuscript drafting; CXD was hematological physician and developed the patient's pharmacotherapy strategy. TYH performed the laboratory examinations and contributed to the manuscript drafting; FPX performed the pathological diagnosis and contributed to the manuscript drafting. JJW responsible for revision of the manuscript; All authors issued final approval for the version to be submitted.

\section{Funding}

The cost of publication was covered by Science and Technology Program Guangzhou, (NO: 201904010020) and the Ethicon Excellence in Surgery Grant (EESG) (No. HZB-20181119-49), China. 


\section{Availability of data and materials}

The datasets used and/or analysed during the current study are available from the corresponding author on reasonable request.

\section{Ethics approval and consent to participate}

This case report did not require review by the Ethics Committee of Guangdong Provincial People's Hospital, Guangzhou, China.

\section{Consent for publication}

Written informed consent for publication of their clinical details and clinical images was obtained from the patient.

\section{Competing interests}

The authors declare that they have no conflicts of interest.

\section{Author details}

'Department of General Surgery, Guangdong Provincial People's Hospital, Guangdong Academy of Medical Sciences, Guangzhou 510080, China. ${ }^{2}$ Department of Hematology, Guangdong Provincial People's Hospital, Guangdong Academy of Medical Sciences, Guangzhou 510080, China ${ }^{3}$ Division of Laboratory Medicine, Guangdong Provincial People's Hospital, Guangdong Academy of Medical Sciences, Guangzhou 510080, China. ${ }^{4}$ Department of Pathology and Laboratory Medicine, Guangdong Provincial People's Hospital, Guangdong Academy of Medical Sciences, Guangzhou 510080, China.

Received: 29 May 2020 Accepted: 13 July 2020

Published online: 04 August 2020

\section{References}

1. Gotlib J. World Health Organization-defined eosinophilic disorders: 2015 update on diagnosis, risk stratification, and management. Am J Hematol. 2015:90:1077-89.

2. Crane MM, Chang CM, Kobayashi MG, et al. Incidence of myeloproliferative hypereosinophilic syndrome in the United States and an estimate of all hypereosinophilic syndrome incidence. J Allergy Clin Immunol. 2010;126: 179-81.

3. Patra S, Samal SC, Chacko A, et al. Cytomegalovirus infection of the human gastrointestinal tract. J Gastroenterol Hepatol. 1999;14:973-6.

4. Dioverti MV, Razonable RR. Cytomegalovirus. Microbiol Spectr. 2016;4:4.

5. Bate SL, Dollard SC, Cannon MJ. Cytomegalovirus seroprevalence in the United States: the national health and nutrition examination surveys, 19882004. Clin Infect Dis. 2016;50:1439-47.

6. Lanzieri TM, Kruszon-Moran D, Amin MM, et al. Seroprevalence of cytomegalovirus among children 1 to 5 years of age in the United States from the National Health and nutrition examination survey of 2011 to 2012. Clin Vaccine Immunol. 2015;22:245-7.

7. Goodgame RW. Gastrointestinal cytomegalovirus disease. Ann Intern Med. 1993;119:924-35.

8. O'Hara KM, Pontrelli G, Kunstel KL. An introduction to gastrointestinal tract CMV disease. JAAPA. 2017;30:48-52

9. Curtis C, Ogbogu P. Hypereosinophilic syndrome. Clin Rev Allergy Immunol. 2016:50:240-51.

10. Ogbogu PU, Bochner BS, Butterfield JH, et al. Hypereosinophilic syndrome: a multicenter, retrospective analysis of clinical characteristics and response to therapy. J Allergy Clin Immunol. 2009;124:1319-25 e3.

11. Azevedo LS, Pierrotti LC, Abdala E, et al. Cytomegalovirus infection in transplant recipients. Clinics (Sao Paulo). 2015;70:515-23.

12. Durand CM, Marr KA, Arnold CA, et al. Detection of cytomegalovirus DNA in plasma as an adjunct diagnostic for gastrointestinal tract disease in kidney and liver transplant recipients. Clin Infect Dis. 2013;57:1550-9.

13. Ichikawa $Y$, Takeuchi M, Yamada M, et al. A case of ischemic colitis induced by hypereosinophilic syndrome. Nihon Shokakibyo Gakkai Zasshi. 2012; 109(12):2074-81.

14. Kobayashi M, Komatsu N, Kuwayama Y, et al. Idiopathic hypereosinophilic syndrome presenting acute abdomen. Intern Med. 2007:46(10):675-8.

15. Boeckh M, Bowden RA, Goodrich JM, et al. Cytomegalovirus antigen detection in peripheral blood leukocytes after allogeneic marrow transplantation. Blood. 1992;80:1358-64.
16. Seo M, Kim DH, Gong EJ, et al. Is Follow-Up Endoscopy Necessary in Upper Gastrointestinal Cytomegalovirus Disease. Medicine (Baltimore). 2016;95: e3389.

17. Boaretti M, Sorrentino A, Zantedeschi C, et al. Quantification of cytomegalovirus DNA by a fully automated real-time PCR for early diagnosis and monitoring of active viral infection in solid organ transplant recipients. J Clin Virol. 2013;56:124-8.

18. Johnson J, Affolter K, Boynton K, et al. CMV disease in IBD: comparison of diagnostic tests and correlation with disease outcome. Inflamm Bowel Dis. 2018;24:1539-46.

\section{Publisher's Note}

Springer Nature remains neutral with regard to jurisdictional claims in published maps and institutional affiliations.
Ready to submit your research? Choose BMC and benefit from:

- fast, convenient online submission

- thorough peer review by experienced researchers in your field

- rapid publication on acceptance

- support for research data, including large and complex data types

- gold Open Access which fosters wider collaboration and increased citations

- maximum visibility for your research: over $100 \mathrm{M}$ website views per year

At BMC, research is always in progress.

Learn more biomedcentral.com/submissions 